\title{
Assessment of Reliability of Rugoscopy for Identification of Gender
}

\author{
Sara Gardezi ${ }^{1}$ \\ BDS \\ Nuzhat Hassan ${ }^{2}$ \\ Sarwat Memon ${ }^{3}$ \\ M.Phil \\ BDS, FCPS
}

OBJECTIVE: To assess rugoscopy for identification of gender in a subset of Karachi population Study design: A Cross sectional Comparative study Place and duration: Dental O.P.D of Ziauddin Hospital Clifton, Karachi from July 2016 -2017. METHODOLOGY: A sample size of 456 individuals aged between 15 and 55 years fulfilling inclusion and exclusion criteria were recruited for the study. The shapes and size of rugae were evaluated on dental casts by classification given by the Kapali et al and Thomas et al respectively. Chi-square test was used to see gender dimorphism in rugae shapes and Mann Whitney U test was used for gender dimorphism in rugae size. A p-value of $\leq 0.05$ was considered significant. The equation given by Bharath et al. was used to determine gender of an individual.

RESULTS: A significant gender dimorphism in rugae shape among Karachi population was observed. The most common rugae shape in males was found to be wavy followed by straight, curved, convergent, divergent and circular rugae. However, the most common rugae shape among females was found to be curved followed by wavy, straight, divergent, convergent and circular rugae. On observing the size of rugae significant gender dimorphism was reported for secondary rugae $(p$-value $=0.045)$. The overall percentage of gender prediction by rugoscopy was $45.6 \%$.

CONCLUSION: Rugoscopy have potential for gender identification and thus may be used for gender identification as an ancillary and supplemental tool in forensic investigation.

KEY WORDS: Rugoscopy, Gender Identification, Forensic identification

HOW TO CITE: Gardezi S, Hassan N, Memon S. Assessment of reliability of rugoscopy for identification of gender. J Pak Dent Assoc 2019;28(3):113-117.

DOI: https://doi.org/10.25301/JPDA.283.113

Received: 14 November 2018, Accepted: 22 April 2019

\section{INTRODUCTION}

$\mathrm{R}$ ugae is a term used in anatomy which refers to a series of ridges that are produced by folding of the wall of an organ. Palatal rugae (PR) are anatomical folds of the oral mucosa present on the anterior third of the palate on each side of the median palatal raphe behind the incisive papillae. Their number, shape, size and location vary on both left and right side of the hard palate and also vary from person to person. ${ }^{1}$ Study of different patterns of the palatal rugae is called Rugoscopy. ${ }^{2}$ Palatal rugae pattern due to post-mortem resistance, individuality, stability, and also low cost marks it ideal for gender identification. ${ }^{2-7}$

Forensic analysts have used various methods like bite marks registration, radiographic analysis, photographs, DNA analysis, Cheiloscopy and Rugoscopy for gender identification. ${ }^{2,3}$ Literature survey revealed that various

1. MPhil Trainee, Department of Oral Biology, Ziauddin University.

2. Professor, Department of Anatomy, Ziauddin University.

3. Assistant Professor, Department of Orthodontics, Ziauddin University.

Corresponding author: "Dr. Sarwat Memon”<sarwatmaqsood@yahoo.com> authors have reported that in certain forensic circumstances there are limitations to identification of the deceased by fingerprints, visual identification, DNA probing and dental records. ${ }^{6-10}$ Many studies support the stability of palatal rugae and suggested that there might be some change in their size due to growth of the palate but their shape remains unaffected. ${ }^{6,7}$ They have been linked with fingerprints because of their stability throughout life and also their potential to regenerate after destruction with exactly the same pattern as before. Literature review reveals rugae variability in different ethnic and population groups. ${ }^{8-16}$ Gardezi S, Hassan N, Memon S and Mughal A in their study found significant difference in rugae pattern amongst five ethnicities of Pakistan. ${ }^{16}$ Studies conducted by Babaji $\mathrm{P}$ et $\mathrm{al}^{13}$, Chopra A et $\mathrm{al}^{14}$ and Subramanian PR et a $\mathrm{l}^{15}$ in their studies used Rugoscopy for gender identification. Different methods are reported in literature for recording the rugae and size pattern. ${ }^{12,16,17}$ In the present study tracing of maxillary cast were used due to low cost, simplicity, and reliability.

Acts of terrorism in Pakistan have increased significantly 
in recent years. Therefore, the Palatal rugae pattern of an individual because of its individuality, postmortem resistance, and stability may be considered as a useful alternative source for gender determination. To the best of our knowledge we were unable to find similar study locally. Our objective was therefore, to assess Rugoscopy for identification of gender in a subset of Karachi population.

\section{METHODOLOGY}

This cross sectional comparative study was conducted at Out Patient Orthodontic Departments of Ziauddin Hospital Karachi from July 2016 to 2017. A written informed consent was obtained from all subjects after explaining the objectives and rationale of the study. We used convenience sampling technique for inclusion of subjects. Pakistani subjects with age groups between 15 to 55 years with complete dentition and good oral hygiene were included in this study. Subjects with a prior history of orthodontic or prosthodontic treatment, severe palatal trauma and congenital syndromes affecting the palate or any surgical procedures performed on the hard palate were excluded from our study. Sample size for this study was calculated by WHO sample size estimation calculator. A sample size of 456 gave the power of $>80 \%$. The study was conducted after the approval from ERC and BASR of Ziauddin University. All the information gathered during the study was kept confidential.

Impression of the subject was taken using impression material (Irreversible hydrocollide alginate, Kromopan) in a plastic perforated tray. The impression was disinfected with $0.5 \%$ hypochlorite for 10 minutes. High strength plaster (ISI Kopo-hard CKH-52 Dental plaster, 0.30 water/powder ratio) was poured in the impression on dental vibrator to avoid air bubbles. The impression was separated from the cast within 30 minutes as it is sufficient time for initial setting. Any portion of the cast that interfered with separation from the tray was trimmed away with the Bard parker knife. The impression was trimmed if required and the base was made with dental plaster using orthodontic base former with $22 \mathrm{~mm}$ of base/cast height. The cast was assigned with patient number. Rugae shape and length was traced using graphite pencil and was analyzed under adequate light and magnification. The palatal rugae were delineated using $0.5 \mathrm{~mm} \mathrm{HB}$ pencil under adequate light (Figure 1). Shapes of rugae on palate were recorded as per classification given by Kapali et al. who described the following rugae patterns (Figure 2). ${ }^{18}$

Size of each rugae was measured from one end to the other end by using a pointed divider as per classification given by Thomas et $\mathrm{al}^{19}$ in 1983 as shown in table 1 and figure 3 .

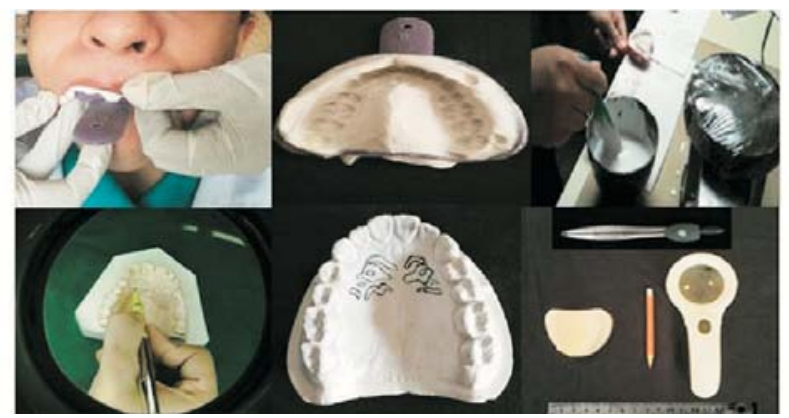

The gender of the individual was determined as per the Figure 1: Showing the different steps of Rugoscopy from the cuurent study

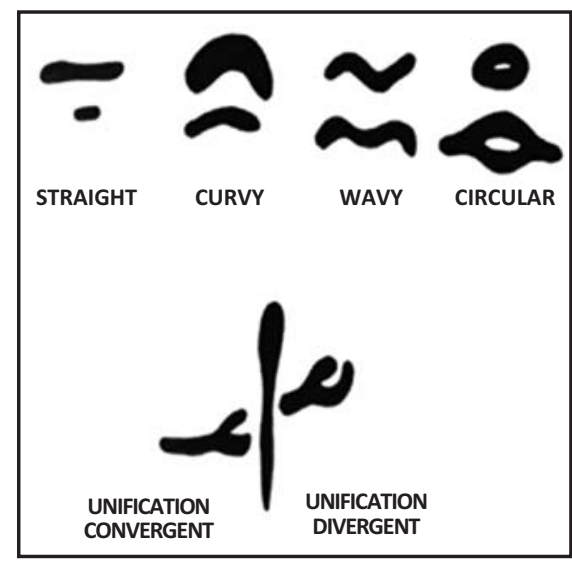

Figure 2: Diagrammatic representation of different types of rugae pattern

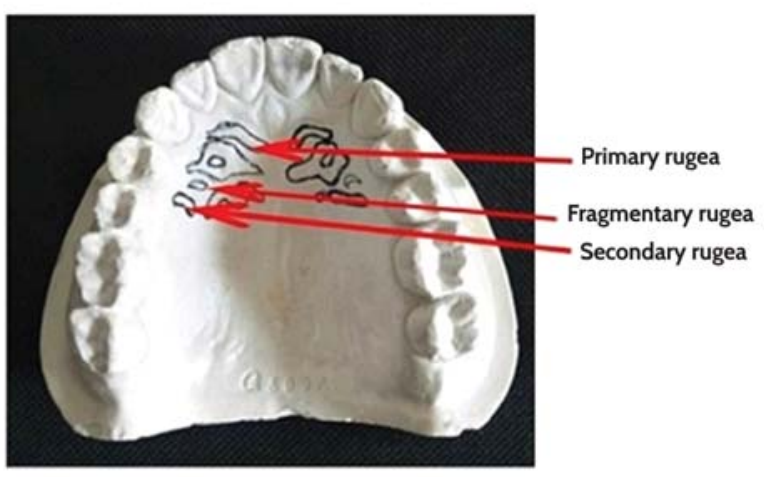

Figure 3: Diagrammatic representation of different sizes of rugae current study as per classification given by Thomas et al

descriptions/equation given by Bharath et $\mathrm{al}^{20}$, in 2011 . Gender $=-0.2620$ (Primaryrugae)- 0.5133 (Secondaryrugae)0.6614 (Fragmentaryrugae) +0.3366 (Straight) +0.4582 (Wavy) +0.4353 (curved) +0.5096 (Circular).

After executing our data in the above equation the gender of the individual was determined with the help of canonical centroids of -0.3088 to 0.3088 . If the product obtained was close to 0.3088 , then the proposed gender was male. But if 
the product obtained was close to -0.3088 then the proposed gender was female.

The collected data was analyzed on SPSS version 20(Armonk, New York, U.S.A). All quantitative variables were presented as the mean and standard deviation and all qualitative variables were presented as the percentage and frequencies. Chi-square test was used for association gender dimorphism in rugae shapes and Mann Whitney U test was used for gender dimorphism in rugae size. Level of significance was set at $\mathrm{p}$-value of $\leq 0.05$.

\section{RESULTS}

Out of 456 participants who underwent this study $203(44.5 \%)$ were females and 253(55.5\%) were males. Chi-Square test was applied to see the gender dimorphism in rugae shape. The most common rugae shape in males was found to be wavy followed by straight, curved, convergent, divergent and circular rugae. However, the most common rugae shape among females was found to be curved followed by wavy, straight, divergent, convergent and circular rugae. A significant gender dimorphism was observed (p-value $<0.05$ ) as depicted in Table 2.

Our data was not following normality assumptions, so Kolmogorov-Smirnov test was run over the data therefore instead of independent sample T test; Mann Whitney U test was used to see the gender dimorphism in rugae length. The secondary rugae were more prevalent as compared to primary and fragmentary rugae in male and female both. However, significant gender dimorphism was reported for secondary rugae $(\mathrm{p}$ - value $=0.045)($ Table 3$)$

Out of 456 participants who underwent the study $28.1 \%$ of males and $32.5 \%$ of females were correctly identified. The overall percentage of gender prediction by Rugoscopy was $45.6 \%$ as shown in Table 4.

\section{DISCUSSION}

Rugea patterns are unique in their morphology. They are considered to be analogous to fingerprints. ${ }^{16}$ Pakistan because of its strategic geographical location and sharing border with various countries has a monumental influx of immigrants. Karachi is a cosmopolitan city of Pakistan with multiple ethnic groups. Therefore, Karachi is a special entity which is needed to be explored.

Several researchers have reported racial and gender differences in palatal rugae shape and size which may help to identify the population especially in disaster victims. ${ }^{17-22}$ The present study evaluated 253 males and 203 females aged 15 to 55 years for gender dimorphism in rugae shapes and length. A statistically significant gender dimorphism was found for rugae shape and length. In our study wavy rugae type predominated in males followed by curved, convergent, divergent and circular while curved pattern dominated in females followed by wavy, straight, divergent, convergent, and circular. ( $p$-value $=0.05$ ) Many authors in the recent years have demonstrated significant relationship between rugae shape and

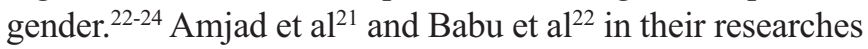
found significant gender dimorphism in rugae shape. In our present study, males had more wavy palatal rugae while females had more curved-shaped rugae pattern. Circular rugae were rarely seen in both genders. Kepali et a ${ }^{18}$ and Venegas et $\mathrm{a}^{23}$ in their studies also reported similar rugea pattern in males. Azab et $\mathrm{al}^{24}$ in Egyptian population observed that males had converging rugea pattern and females had more curved rugea pattern. Fahmi et $\mathrm{al}^{25}$ reported that Saudi females converging rugea type while males had a significantly greater number of circular rugea shape. In contrast to our study Shetty et $\mathrm{al}^{26}$ reported curved rugea pattern in Indian than Tibetan males while Tibetan females had predominant wavy rugea patterns than Indian females. Other studies have reported no significant gender dimorphism between rugae patterns. Bajracharya et $\mathrm{al}^{27}$ found no statistically significant gender dimorphism in Nepalese subjects.

In our study secondary rugea was more predominant followed by primary and fragmentary rugea type. Furthermore, significant gender dimorphism was observed for secondary rugae. $(p-$ value $=0.045)$. However, Azab et $\mathrm{al}^{24}$ in Egyptian population, Fahmi et $\mathrm{al}^{25}$ in Saudi population and Selvamani et a ${ }^{28}$ in Indian population reported primary rugea to the prevalent then secondary rugea. Surekha et $\mathrm{al}^{29}$ found in their study primary rugae to be more common in Kerala population, whereas secondary rugae were more common in Manipuri population.

On discriminate analysis of size and shape of palatal rugae, an equation proposed by Bharath et $\mathrm{a}^{20}$ was used. Bharath et $\mathrm{al}^{19}$ in Indian population found the percentage of gender prediction to be $78 \%$ accurate. On the contrary, when the discriminate analysis of size and shape of palatal rugae developed by Bharath et a ${ }^{19}$ was applied to our sample, the percentage of gender prediction correctly was found to be only $45.6 \%$. Saadeh et $\mathrm{al}^{30}$ in their multivariate analysis combined, four linear and one angular rugae measurements and correctly predicted gender in $71.4 \%$ of the sample. Ahmed AA and Hamid $\mathrm{A}^{31}$ using logistic regression analysis in the Sudanese Arabs reported gender predictive value of $60 \%$ using dimensions and orientations and predictive value of $58 \%$ using shapes alone. Saraf A et al ${ }^{32}$ in their study used logistic regression analysis and correctly predicted gender in $99.2 \%$ of their sample using rugae shapes only. This suggests that to improve the accuracy of gender 
prediction, a new standard gender prediction equation using logistic regression analysis should be developed for our population.

It was single-center study hence the results cannot be generalized for the Karachi population. We recommend that multicenter prospective nationwide studies including different ethnicities to further strengthen and validate results of our study. In addition, a data bank of palatal rugae can be established as they may serve as an ante- mortem record. To improve the accuracy for gender identification, a new standard gender prediction equation should be developed by using advance statistical method for our population.

\section{CONCLUSIONS}

Rugoscopy have potential for gender identification and thus can be used for gender identification as an ancillary and supplemental tool in forensic investigation.

\section{CONFLICT OF INTEREST}

None declared

\section{REFERENCES}

1. Santos, K. C.; Clemente, M. S. \& Serra, M. C. Evaluation of a digital methodology for human identification using palatal rugoscopy. Braz. J. Oral Sci., 2011;10:199-203.

2. Bhullar A, Kaur RP, Kamat MS. Palatal Rugea - an Aid in Clinical Dentistry. J Forensic Res 2011; 2:124.

https://doi.org/10.4172/2157-7145.1000124

3. Nagalaxmi V, U Sridevi, Naga Joythi M, Ch Lalitha, Kotya NM, Kodangal S. Cheiloscopy, Palatoscopy and Odontometrics in Sex Prediction and Dis-crimination - a Comparative Study. Open Dent J. 2015;8:269-79

https://doi.org/10.2174/1874210601408010269

4. Sheikhi M, Zandi M, Ghazizadeh M. Assessment of palatal rugae pattern for sex and ethnicity identification in an iranian population. Dent Res J 2018;15:50-6.

https://doi.org/10.4103/1735-3327.223611

5. Kommalapati RK, Katuri D, Kattappagari KK, Kantheti LPC, Murakonda RB, et al. Systematic Analysis of Palatal Rugae Pattern for Use in Human Identification between Two Different Populations. Iran J Public Health. 2017;46:602-07.

6. Mustafa AG, Allouh M, Tarawneh I, Alrbata R. Morphometric analysis of palatal rugae among Jordanians: further evidence of worldwide palatal rugae individuality. Aust J Sci. 2014;46:53-63. https://doi.org/10.1080/00450618.2013.804947

7. English WR, Robinson SF, Summitt JB, Oesterle LJ, Brannon RB,
Morlang WM. Individuality of human palatal rugae. J Forensic Sci. 1988;33:718-26.

https://doi.org/10.1520/JFS12479J

8. D. Shukla, A. Chowdhry, D. Bablani, P. Jain, R. Thapar. Establishing the reliability of palatal rugae pattern in individual identification (following orthodontic treatment). J Forensic Odontostomatol. 2011;29: 20-9.

9. Mutalik VS, Menon A, Jayalakshmi N, Kamath A, Raghu AR. Utility of cheiloscopy, rugoscopy, and dactyloscopy. J Forensic Dent Sci. 2013;5:2-6.

https://doi.org/10.4103/0975-1475.114535

10. Chugh A, Narwal A. Oral mark in the application of an individual identification: From ashes to truth. J Forensic Dent Sci. 2017;9:51-5. https://doi.org/10.4103/jfo.jfds_103_15

11. Jain A1, Chowdhary R. Palatal rugae and their role in forensic odontology. J Investig Clin Dent. 2014;5:171-78.

https://doi.org/10.1111/j.2041-1626.2013.00150.x

12. Pappu BT, Gopinathan TA, Naduvakattu B. Assessment of different palatal rugae patterns in gender identification. Int J Oral Care Res 2018;6:17-20.

13. Babaji P, Jalal SA, Kamalaksharappa SK. Evaluation of palatal rugae pattern in identification and sex determination in Indian children. Pesq Bras Odontoped Clin Integr 2018;18:e3944.

https://doi.org/10.4034/PBOCI.2018.181.39

14. Chopra A, Rao NC, Gupta N, Vashisth S. Palatal rugae and arch length: A tool in gender determination. Univ Res J Dent 2013;3:54-9. https://doi.org/10.4103/2249-9725.122301

15. Subramanian PR, Jagannathan NI. Palatal rugoscopy as a method of sex determination in forensic science. Asian J Pharm Clin Res2015;8:136-8.

16. Gardezi S, Hassan N, Memon S, Mughal A, Rugroscopy in Five Different Ethnic Group of Pakistani Population. Pak J Med Dent 2018; $7 ; 11-14$.

17. Jacob RF, Shalla CL. Postmortem identification of the edentulous deceased: Denture tissue surface anatomy. J Forensic Sci 1987;32:698702.

https://doi.org/10.1520/JFS12375J

18. Kapali S, Townsend G, Richards L, Parish T. Palatal rugae pattern in Australian Arborigines and Caucasians. Aus Dent J. 1997;42:129-33 https://doi.org/10.1111/j.1834-7819.1997.tb00110.x

19. Thomas CJ, Kotze TJ. The palatal rugae pattern: A new classification. J Dent Assoc S Afr. 1983;38:153-57.

20. Bharath ST, Kumar GR, Dhanapal R, Saraswathi T. Sex determination by discriminant function analysis of palatal rugae from a population of coastal Andhra. J Forensic Dent Sci. 2011;3:58-62. https://doi.org/10.4103/0975-1475.92144 
21. Amjad A, Hussain S, Rehman A, Hassan SH. Role of palatal rugae pattern in forensic identification of individuals. Pak Orthodo J. 2016;8:104-08.

22. Babu GS, Bharath TS, Kumar NG. Characteristics of palatal rugae patterns in west Godavari population of India. J Clin Diagn Res. 2013;7:2356-9.

23. Venegas VH, Valenzuela JSP, López MC, Galdames ICS. Palatal Rugae: Systematic Analysis of its Shape and Dimensions for Use in Human Identification. Int. J. Morphol. 2009;27:819-25. https://doi.org/10.4067/S0717-95022009000300029

24. Azab SM, Magdy R, Sharaf El Deen MA. Patterns of palatal rugae among adult Egyptian population. Egypt J Sci. 2016;6:78-3. https://doi.org/10.1016/j.ejfs.2015.01.006

25. F.M. Fahmi, S.A. Al-Shamrani, Y.F. Talic. Rugae pattern in a Saudi population sample of males and females. Saudi Dent J 2001;13: 92-5

26. Shetty SK1, Kalia S, Patil K, Mahima VG. Palatal rugae pattern in Mysorean and Tibetan populations. Indian J Dent Res. 2005;16:51-5.

27. Bajracharya D, Vaidya A, Thapa s. \& Shrestha S. Palatal rugae pattern in nepalese subjects. Orthodo J Nepal 2013;3:36-9.

https://doi.org/10.3126/ojn.v3i2.10076
28. Selvamani M, Hosallimath S, Madhushankari, Basandi PS, Yamunadevi A. Dimensional and morphological analysis of various rugae patterns in Kerala (South India) sample population: A crosssectional study. J Nat Sci Biol Med. 2015;6:306-09.

https://doi.org/10.4103/0976-9668.159985

29. R. Surekha, K. Anila, V. S. Reddy, S. Hunasgi, S. Ravikumar, and N. Ramesh. Assessment of palatal rugae patterns in Manipuri and Kerala population. J Forensic Dent Sci. 2012;4:93-6.

https://doi.org/10.4103/0975-1475.109896

30. Saadeh M1, Ghafari JG1, Haddad RV2, Ayoub F. Sex prediction from morphometric palatal rugae measures. J Forensic Odontostomatol. 2017;1:9-20.

31. Ahmed AA, Hamid A. Morphological study of palatal rugae in a Sudanese population. Int J Dent. 2015;2015:650648.

https://doi.org/10.1155/2015/650648

32. Saraf A, Bedia S, Indurkar A, Degwekar S, Bhowate R. Rugae patterns as an adjunct to sex differentiation in forensic identification. J Forensic Odontostomatol. 2011;29:14-9. 